\title{
DECOLONIZAR EL SABER EN LA INVESTIGACIÓN EN EDUCACIÓN: EL PENSAMIENTO-OTRO COMO ESTRATEGIA EPISTÉMICA PARA LA PRODUCCIÓN ACADÉMICA DIVERSIFICADA
}

\author{
DECOLONIZING KNOWLEDGE IN RESEARCH ON EDUCATION: THE THOUGHT OTHER AS AN EPISTEMIC STRATEGY FOR THE DIVERSIFIED
} ACADEMIC PRODUCTION

DECOLONIZING KNOWLEDGE IN RESEARCH ON EDUCATION: THE THOUGHT OTHER AS AN EPISTEMIC STRATEGY FOR THE DIVERSIFIED ACADEMIC PRODUCTION

\author{
PANOTTO, Nicolás Esteban ${ }^{1}$ \\ CECCHETTI, Elcio ${ }^{2}$ \\ TEDESCO, Anderson Luiz ${ }^{3}$
}

\section{RESUMEN}

En este trabajo buscamos analizar cómo la colonialidad del saber estructura los centros universitarios, especialmente en la producción de trabajos investigativos en educación. Inicialmente, desarrollaremos algunos de los replanteos que han ofrecido los pensadores del llamado "giro decolonial", en torno a una revisión de las comprensiones epistemológicas imperantes en el continente latinoamericano y los diversos modos de construcción de un conocimiento-otro como crítica no sólo de los marcos epistemológicos hegemónicos, sino también de las implicancias socio-políticas y culturales. A partir de allí, examinaremos el lugar del intelectual y de las instituciones académicas frente al reto de la reconceptualización del trabajo investigativo en el campo de la educación. Metodológicamente orientado en una reflexión crítica a partir de estudio bibliográfico, argumentamos a favor de la necesidad de una decolonización de la universidad, que deconstruya las visiones monopólicas del mundo para dar cuenta de la pluralidad de mundos-posibles, más allá de las cosmovisiones occidentales y modernas. Esto se realiza replanteando no sólo los puntos de partida epistemológicos sino también a partir de cambios concretos a nivel institucional, que involucran diseños curriculares más flexibles y plurales, y la producción académica diversificada, específicamente, en este caso, en el marco de la investigación en educación, para que ésta articule diversas epistemologías y no sólo las corrientes de la academia europea monopólica.

Palabras-claves: Decolonialidad del saber. Investigación en Educación. Epistemología.

\begin{abstract}
In this work we aim to analyze how the coloniality of knowledge structures the university centers, especially the production of research works in education. Initially, we developed some of the themes offered by the thinkers of the so-called "decolonial gyro" about a revision of the epistemological understandings prevailing in the Latin American continent and the different ways to constructing a knowledge-other as a criticism not only of the hegemonic epistemological bases, but also of the socio-political and cultural implications. From this, we analyze the place of the intellectual and academic institutions in the face of the challenge of reconceptualizing research work in the field of education. Methodologically oriented by a critical reflection from a bibliographical study, we argue in favor of the need for a decolonization of the university, that deconstructs the monopolistic visions of the world to account for the plurality of possible worlds, going beyond the western and modern cosmovisions. This is done by rethinking not only the epistemological points of departure but also from concrete transformations at the institutional level, which includes more flexible and plural curriculum designs, and the diverse academic production, specifically in this case, in regard to research in education, for this to articulate various epistemologies and not only the currents of the European monopoly academy.
\end{abstract}

\footnotetext{
${ }^{1}$ Grupo de Estudios Multidisciplinarios sobre Religión e Incidencia Pública - GEMRIP, Santiago - Chile.

2 Universidade Comunitária da Região de Chapecó - UNOCHAPECÓ, Chapecó/SC-Brasil.

${ }^{3}$ Universidade Comunitária da Região de Chapecó - UNOCHAPECÓ, Chapecó/SC-Brasil.
} 
Keywords: Decoloniality of knowledge. Education Research. Epistemology.

\begin{abstract}
RESUMO
Neste trabalho buscamos analisar como a colonialidade do saber estrutura os centros universitários, especialmente a produção de trabalhos de pesquisa em educação. Inicialmente, desenvolvemos alguns dos temas oferecidos pelos pensadores do chamado "giro decolonial" acerca de uma revisão das compreensões epistemológicas imperantes no continente latino americano e os diversos modos de construção de um conhecimento-outro como crítica não somente das bases epistemológicas hegemônicas, mas também das implicações sócio-políticas e culturais. A partir disso, analisamos o lugar do intelectual e das instituições acadêmicas frente ao desafio de reconceitualizar o trabalho de pesquisa no campo da educação. Metodologicamente orientado por uma reflexão crítica a partir de estudo bibliográfico, argumentamos a favor da necessidade de uma decolonização da universidade, que descontrua as visões monopólicas do mundo para dar conta da pluralidade de mundo-possíveis, indo além das cosmovisões ocidentais e modernas. Isso se realiza repensando não somente os pontos de partida epistemológicos mas também a partir de transformações concretas em nível institucional, o que inclui desenhos curriculares mais flexíveis y plurais, e a produção acadêmica diversificada, especificamente, neste caso, no que tange a pesquisa em educação, para que esta articule diversas epistemologias e não somente as correntes da academia europeia monopólica.

Palavras-chave: Decolonialidade do saber. Pesquisa em Educação. Epistemologia.
\end{abstract}

\title{
INTRODUCCIÓN
}

La corriente bajo el nombre de giro decolonia/ resume su crítica a las dinámicas socio-políticas coloniales aún presentes en el mundo globalizado contemporáneo a través de la siguiente tríada: colonialidad del ser, colonialidad del poder y colonialidad del saber (QUIJANO, 2011). Básicamente, sostiene que los procesos coloniales distan de ser un elemento histórico que quedó enterrado en el pasado junto a los complejos procesos de independencia de los países latinoamericanos. Por el contrario, sus matrices, que concentran las relaciones entre las fuerzas centrales con las geografías conquistadas, aún persisten, aunque ya no desde dinámicas coercitivas sino más bien desde configuraciones de sentido sobre la subjetividad, el saber y el poder, que afectan tanto las relaciones geopolíticas como las disposiciones microfísicas y cotidianas de los sujetos y colectivos.

Estas tres categorizaciones sirven para dar cuenta de los modos en que aún se sostienen las dinámicas de poder global que nacieron con la modernidad y el capitalismo occidental postconquista. La colonialidad del poder refiere a los mecanismos institucionales de gobernabilidad como también a los procesos de clasificación social, es decir, de reconocimiento de las lógicas de dominio que prevalecen en el contexto globalizado. Uno de los dispositivos más significativos es el de los procesos de racialización (QUIJANO, 2000), aunque también se pueden incluir las propias instituciones políticas modernas - como el lugar del Estado y la idea de nación/nacionalidad como marco hegemónico de subjetividad (BHABHA, 2010) - y las prácticas políticas burocratizadas desde estas mismas.

La colonialidad del ser involucra más concretamente las dimensiones ontológicas dominantes y las operaciones tanto de codificación como de legitimación de la alteridad. Aquí podríamos remitir al concepto de orientalismo de Edward Said (2016), donde la construcción de la noción sobre Oriente actúa como espejo legitimador de la "identidad occidental", lo que también sucede con las demarcaciones sobre "Io latinoamericano" en los centros de formación latinoamericanista más importantes de los países centrales (Canclini, 2001, 2002). En otros términos, las representaciones 
identitarias actúan como nominaciones inscritas en juegos de poder entre las segmentaciones coloniales (internas y externas a la región) que tratan de homogeneizar su sentido y las operaciones de identificación heterodoxas a las figuras monopólicas.

Por último, la colonidalidad del saber se extiende sobre los parámetros de construcción de conocimiento y todos sus campos de incidencia (la academia, la escuela, los intelectuales, y más concretamente los diversos procesos de valoración epistemológica), donde las nociones de objetividad y veracidad van de la mano de una episteme ligada a la supuesta sutura de lo racional, lo ilustrado y todos sus dispositivos académicos, los cuales, a su vez, sirven a la legitimación de lo moderno y occidental como marcos hegemónicos de sentido.

Estos dispositivos de colonialidad se inscriben en dos campos situacionales centrales a tener en cuenta para un abordaje decolonial. Primero, tal como mencionamos, ellos evidencian que los procesos de colonialidad no culminaron con las empresas independentistas, sino que la conquista del "nuevo mundo" fue solo el epicentro de un proceso que venía gestándose desde antes, con las transformaciones en las lógicas imperiales europeas que se extienden hasta hoy día, y donde los valores, jerarquizaciones y cosmovisiones occidentales pasaron a ser parte de la amalgama social latinoamericana, así como de todo el mundo globalizado. En segundo lugar, no se puede entender el afianzamiento y alcance de la modernidad fuera del marco de la colonialidad. La construcción y sujeción del Otro-colonial fueron condiciones para el establecimiento de la modernidad, tanto a nivel cosmovisional como institucional y geopolítico.

En este trabajo nos concentraremos más específicamente en el estudio de la tercera categoría, es decir, la colonialidad del saber, y cómo ella actúa dentro de los centros universitarios, especialmente en la producción de trabajos investigativos en educación. Inicialmente, desarrollaremos algunos de los replanteos que han ofrecido los pensadores del llamado "giro decolonial", en torno a una revisión de las comprensiones epistemológicas imperantes en el continente latinoamericano y los diversos modos de construcción de un conocimiento-otro como crítica no sólo de los marcos epistemológicos hegemónicos, sino también de sus implicancias socio-políticas y culturales. A partir eso, examinaremos el lugar del intelectual y el de las instituciones académicas frente el reto de la reconceptualización del trabajo intelectual en el campo de la educación. Metodológicamente orientado en una reflexión crítica a partir de estudio bibliográfico, argumentamos a favor de la necesidad de una decolonización de la universidad, que deconstruya las visiones monopólicas del mundo para dar cuenta de la pluralidad de mundos-posibles, más allá de las cosmovisiones occidentales y modernas.

\section{HACIA UNA EPISTEMOLOGÍA DECOLONIAL PARA UN CONOCIMIENTO-OTRO}

La identificación de la colonialidad del saber plantea que las dinámicas epistemológicas van siempre de la mano de los procesos socio-políticos (colonialidad del poder) y de los mecanismos de construcción identitaria (colonialidad del ser). Más concretamente, se evidencia la existencia de un conjunto de comprensiones epistémicas que responden a los encuadres simbólicos, discursivos, ideológicos y cosmovisionales de los contextos geopolíticos actuales, en lo que refiere a la promoción 
de valores morales, culturales y políticos representativos de las lógicas (no sólo grupos) poscoloniales. Algunas de las características de este marco epistémico son las siguientes:

a) Tiene su origen en 1492 con la conformación del sistema-mundo capitalista, donde la separación entre lo humano y la naturaleza sirve como fundamento de las lógicas de explotación, no sólo sobre la naturaleza sino sobre lo considerado "no humano", es decir, los pueblos indígenas.

b) Esto da lugar a los dualismos típicos de la modernidad, como la distinción sujeto-objeto, que lleva, por un lado, a la construcción de un sujeto universal como plataforma antropológica eurocéntrica de la modernidad que deslegitima cualquier otro modo de subjetividad que no sea occidental, y por otro, a la construcción de un proceso de clasificación socio-cultural que ubica al ser humano (desde su definición eurocéntrica) en un estatus de dominio sobre el resto de las realidades, objetos, universos, cosmovisiones y otros pueblos.

c) La "superioridad" auto atribuida por la mentalidad moderna, de su estatus ontológico identitario, y la idea de progreso en las naciones coloniales, sitúa al racionalismo ilustrado y el positivismo científico como los epicentros universales de la construcción del conocimiento. Dicha epistemología predomina en las prácticas de clasificación deductiva, las determinaciones positivistas, la ubicación de la razón como el epicentro del saber y de la ciencia como poseedora de la "verdad" absoluta, transparente y neutral, que a su vez representa la naturalización de las propias relaciones sociales (LANDER, 2011; PANIKKAR, 2009).

d) De aquí que toda epistemología "no racional" o inductiva, ligada a otros campos de la sensibilidad humana - el arte, lo estético, lo oral, la narrativa, etc.- son comprendidos como modos primitivos o secundarios, por lo cual son desestimadas como posibles mediaciones epistémicas y formas de intervenir en la realidad. Esto involucra, además, la exclusión de toda propuesta epistémica alternativa que no responda a los cánones de la racionalidad, deductividad y positivismos modernos.

Por todo esto, una descolonización del saber debe ir de la mano de una descolonización epistemológica. Más aún, cualquier proceso de construcción de conocimiento conlleva intrínsecamente un locus de operatividad socio-política. Como afirma Claros (2011, p. 6): "toda disputa por la significación del mundo es una lucha política, y la epistemología, en la medida que encuentra su razón de ser en la crítica de las diferentes formas de significar el mundo es parte de la lucha política". En esta línea, por ejemplo, fueron los estudios subalternos los primeros en plantear la búsqueda de nuevos códigos en los ejercicios académicos. El campo más desarrollado por este colectivo fue el de una nueva historiografía que ponga entre paréntesis los legados históricos coloniales, a través del rastreo de relatos, narrativas e "pequeñas historias" que fueron dejadas de lado por la "historia oficial" de los imperios sobre los pueblos subalternizados. Significa aplicar un ejercicio de rescate de fragmentos que hagan colapsar la universalización de los procesos académicos monopólicos, a partir de los cuales se pretende sostener narrativas políticas coloniales, a costa del silenciamiento de las disidencias cotidianas.

Todo esto conlleva reconocer la complejidad de las dinámicas de poder y su necesaria deconstrucción a partir de las inconsistencias y contingencias inherentes a ellas. Así como se registra 
lo subrepticio o la microfísica de los poderes (FOUCAULT, 2008) (o sea, de cómo dichas dinámicas permean no sólo a través de jerarquías y procesos de subida/bajada, arriba/abajo, centro/periferia, sino también - y especialmente - en modos de convivencia, construcciones subjetivas e instancias cotidianas), de la misma manera se evidencian caminos alternativos y heterogéneos de resistencia y contrapoder que parten desde construcciones de sentido y conocimiento heterodoxas, entre las fisuras del mismo "sistema".

De Sousa Santos (2010) denomina dicho proceso como el paso de un pensamiento abismal, característico de la modernidad (donde el conocimiento occidental despliega un sistema de distinción entre lo visible e invisible, quedando esto último excluido como posible fundamento del conocimiento debido a la imposibilidad de la copresencia de ambos elementos), a uno posabismal como pensamiento ecológico (o ecología de saberes), donde los procesos epistemológicos son tan variados como la pluralidad de experiencias histórico-culturales.

Sobre las propuestas epistémicas alternativas y críticas planteadas desde las lecturas decoloniales, el trabajo de Walter Mignolo $(2010 ; 2013)$ es uno de los más reconocidos. Este filósofo argentino define colonialidad como una compleja matriz donde se entrelazan diversos niveles (economía, autoridad, naturaleza, género y sexualidad, subjetividad y conocimiento), sostenida en tres pilares: el conocer (epistemología), el entender o comprender (hermenéutica) y el sentir (aesthesis). Por otro lado, traza la existencia de una relación entre colonialidad y racionalidad moderna, definiendo esta última como la construcción de una totalidad que anula toda diferencia o posibilidad de cimentación desde otras totalidades.

Por todo esto, se requiere de un proyecto descolonial como el desprendimiento de las categorías de conocimiento colonial. Mignolo (2010) realiza una diferenciación entre emancipación (como enmarque liberal que atiende a las pretensiones de la burguesía) y liberación (como categoría más amplia que busca caminos de desprendimiento con el proyecto emancipador europeo). El concepto de descolonización, según Mignolo (2010), va aún más allá de la liberación, ya que implica tanto a colonizadores como a colonizados (como proponía Fanon), por lo que incluye en sí la emancipación/liberación. Pero como la emancipación es un proyecto moderno ligado a la burguesía liberal europea, el camino se encuadra en la liberación/descolonización, que incluye el concepto racional de emancipación.

De aquí propone una estrategia de desprendimiento, que comprende la desnaturalización de los conceptos y los campos conceptuales de la colonialidad. Esto no significa ignorar o negar el peso real de las estructuraciones geopolíticas afianzadas en los tuétanos de los sistemas imperantes, sino utilizar las estrategias imperiales con propósitos decoloniales. En otros términos, es hacerle el juego al sistema desde sus propias reglas. El desprendimiento también involucra descreer que la razón imperial puede dar por sí misma una razón liberadora (como por ejemplo las propuestas de descolonización que utilizan el marxismo, que no representan un desprendimiento radical sino más bien una "emancipación radical", ya que el marxismo ofrece un "contenido" distinto, pero no así una "lógica" distinta).

El proyecto de decolonización supone un desplazamiento de la hegemonía teo/ego-lógica del imperio hacia una geo-política y una lógica del conocimiento que nace de una desclasificación y 
desidentificación de los sujetos imperialmente negados, como una política y epistemología que disloca el control político y económico del neoliberalismo y el capitalismo, ambos marcos del proyecto imperial.

El proceso de decolonización comienza cuando los actores que habitan las lenguas y las identidades negadas toman conciencia de los efectos de la colonialidad en el ser, el cuerpo y el saber. Esto no significa evocar a un elemento/actor/proyecto externo cuasi mesiánico, sino a la inscripción de una exterioridad que visibilice la diferencia del espacio de la experiencia y el horizonte de expectativas inscriptos en el espacio colonial. Vale aclarar que la propuesta de Mignolo está lejos de un relativismo cultural. Lo que presenta, más bien, es el cuestionamiento de un posicionamiento desde las fronteras divisorias; o sea, la frontera que une y separa la modernidad/colonialidad.

Aquí la propuesta central de su obra: el pensamiento fronterizo. Esta epistemología evoca a la pluri-versidad y di-versidad de la dinámica entre los espacios de experiencia y los horizontes de expectativa suscriptos en el espacio colonial/moderno. El pensar fronterizo insiste en que la descolonización no vendrá de los conflictos suscitados desde la coerción imperial sino por los espacios de experiencia y los horizontes de expectativa generados desde de la subalternidad. El pensamiento crítico decolonial conecta la pluri-versidad de las experiencias encerradas en los marcos coloniales con el proyecto uni-versal del desprendimiento constante de los horizontes imperiales, lo cual establece una propuesta que va más allá de la implementación de un modelo dentro de las categorías modernas (derecha, centro, izquierda), hacia la puesta en evidencia de los espacios subversivos inscriptos en la acción de los agentes colonizados entre las fisuras del sistema imperial, evidenciando otros modos de ser, de convivir, de hacer política, de comprender el mundo, de performances de construcción de saberes, habitando inclusive el propio sistema colonial.

Con este concepto, lo que Mignolo (2013) plantea es que la colonialidad del saber puede ser deconstruida, cuestionada y contaminada desde adentro, potenciando la "diferencia colonial" como una manera de "implosionar" el saber hegemónico desde sus mismas coyunturas, es decir, desde una diferenciación interna.

Los posicionamientos de Mignolo traslucen dos perspectivas presentes dentro del giro decolonial, pero que no son necesariamente excluyentes una de la otra. Mientras la propuesta de Mignolo plantea una crítica a las epistemes hegemónicas a partir del resquebrajamiento que produce la diferencia colonial en el discurso operante, Walsh enfatiza más bien sobre un posicionamiento-otro que se focaliza más en la localidad epistemológica que en un efecto fronterizo dentro de los marcos hegemónicos.

Podríamos considerar que dicho posicionamiento-otro no sería posible sin la lógica de diferencialidad colonial que deconstruye las fronteras del sistema-mundo y que dan cuenta de la emergencia de esas localidades alternativas y contrahegemónicas, como tampoco podríamos identificar dicha diferencia sin un lugar-otro que revele una lógica que subvierte los sentidos establecidos.

Una epistemología fundada en el pensamiento-otro conlleva tres aspectos centrales, que a su vez implican tres instancias críticas con la colonialidad del saber. Primero, que el conocimiento es siempre una búsqueda en medio de los hiatos de la propia realidad, que la atraviesan como indagación siempre abierta, y que emerge como una representatividad pasajera de la indecibilidad que lo 
atraviesa. Por ende, la teoría nunca constituye un conjunto normativo de explicaciones y determinaciones universalizables, sino intuiciones transitorias sobre la realidad y exploraciones que nunca se dan por una simple intuición racional, sino que es motivada por preocupaciones sociales, perspectivas ideológicas y marcos políticos y culturales.

Segundo, es una epistemología que rompe la dicotomía entre teoría y praxis. Esta distinción colonial ha servido para diversas causas: desde legitimar clasificaciones de estratificación social (academia versus política, occidente como productor de conocimiento versus tercer mundo como ejecutor), hasta la división entre objeto/sujeto, que ha fundamentado la cosificación de la realidad y la abstracción neutralizante de los enunciados científicos. Una epistemología desde el pensamiento-otro entiende a la praxis como el "horizonte de empleo de la teoría" (CLAROS, 2011, p. 107), donde historia y construcciones de sentido no son dos dimensiones separadas que pertenecen ontológicamente a campos distinguibles (como puede ser praxis/política y teoría/academia) sino instancias que no pueden comprenderse una sin la otra. La teoría es un conjunto de enunciados pero que a su vez "presiona" la representación establecida de la praxis, así como la dinámica de esta última cuestiona cualquier conjunto cognitivo.

Por último, esta epistemología no pretende ser el reflejo de un universo establecido donde hay que "descubrir" sus características y procesos, ya definidos por un estatus ontológico inamovible. Más bien, las teorías son la muestra de una pluralidad de universos. Más aún, como hemos afirmado, las propias dinámicas epistemológicas son en sí mismas construcciones de universos-otros, ya que su ejercicio no sólo analiza y categoriza, sino que articula, crea y subvierte.

\section{LA DECOLONIALIDAD DEL SABER Y EL TRABAJO INVESTIGATIVO EN EL CAMPO DE LA EDUCACIÓN}

A partir de lo anterior, el primer campo a analizar es el lugar del intelectual frente al reto de la reconceptualización del trabajo investigativo. Mignolo (2010) afirma que, aunque la modernidad no sea un fenómeno estrictamente europeo, su retórica es construida por filósofos, académicos y políticos europeos. La modernidad, entonces, involucra una colonización del tiempo y del espacio, e impone una lógica dualista entre sujeto-objeto, donde se delimita la frontera con un Otro autodeterminante de la propia identidad europea.

Uno de los referentes que más ha trabajado sobre el rol de los intelectuales fue Frantz Fanon. Este pensador, vinculado a la teoría poscolonial y los movimientos antinacionalistas de mitad de siglo $\mathrm{XX}$, plantea que las fuerzas coloniales no sólo actúan a través de la imposición de un tipo de cultura, sino que realizan una especie de vaciamiento y tergiversación de la historia de los pueblos, con el intento no sólo de ejecutar un proceso de coerción, sino que los mismos pueblos subyugados lleguen al punto de reconocer que "deben ser salvados de ellos mismos". Es decir, que es su propia historia la que los lleva donde están, y no la acción de alguna fuerza colonial o foránea. Más bien, estas últimas vienen a salvarlos.

De aquí - sostiene Fanon (1994) - el rol del "intelectual colonizado" es sumergirse en las entrañas de su pueblo, con el objetivo de rescatar las narrativas locales, pero no para absolutizar una 
particularidad sino ubicarla en un contexto mayor que cuestione la lógica de poder colonial en su dimensión totalitaria. Por esta razón, el rol del intelectual, desde esta perspectiva, implica una radicalización del pensamiento local, pero no con el propósito de fomentar una folklorización y exotización de la alteridad a la que responde, sino de evocar una localización que desarticule y disloque las concepciones universalizadas sobre lo cultural y lo político. Con ello se busca disputar las epistemes coloniales, cuyo poder reside no sólo en la coerción de una cosmovisión absolutizada sino en la ubicación de un locus subalterno y sus modos de construir conocimiento con un doble objetivo, que parecería paradójico: socavar el estatus ontológico de las epistemes universales a través de una confrontación con una alteridad que corroe su monolingüismo.

La propuesta de Fanon apunta a cuestionar la misma lógica absolutizante de los particularismos como entidades homogéneas y dispersas, abriendo así la posibilidad de ser ubicadas como segmentaciones que detenten un estatus de superioridad por sobre otras, a través de la supuesta sutura de sus límites. Por ello, el valor del trabajo intelectual significa destacar el valor de la pluralidad y la diversidad, no como un simple ejercicio comparativo o confrontativo, sino para demostrar que las epistemes se construyen desde una confluencia, mezcla y hasta caótico encuentro de presencias y modos de construcción de sentido.

Una decolonización del trabajo intelectual implica, entonces, la transformación de sus propios códigos y de los métodos empleados. Nelly Richard, analizando los Estudios Culturales desde la idea de "política de trabajo intelectual" desarrollada por Stuart Hall, afirma que no sólo deben transformarse las categorías de conocimiento o regímenes de textualidad sino, por sobre todas las cosas, las reglas de vinculación entre los conceptos teóricos, las formas sociales y las cosmovisiones culturales.

El segundo campo a analizar es el de la propia institucionalidad académica. El modelo monopólico de universidad contemporánea también responde a una mirada colonial sobre la realidad. Las universidades continúan siendo espacios de reproducción de una visión hegemónica del mundo (LANDER, 2011), en la que se valida una única forma de conocimiento, es decir, la ratio eurocentrada (PALERMO, 2015). Ella no es apenas un conjunto de conocimientos o reglas metodológicas de investigación; representa, más bien, un fenómeno cultural poderoso, una institución político-social portadora de una cosmovisión concreta, que se auto-concibe como universal, neutra y veraz. Dicha visión de la ciencia es un "modo de pensar y ver la realidad", una forma "específica y restricta de pensamiento", justamente por ser "monocultural, monoracional y prácticamente autosuficiente" (PANIKKAR, 2009, p. 30).

En el modelo universitario vigente prepondera una visión privilegiada del cientificismo positivista, donde inclusive las ciencias humanas pierden su instancia crítica a partir de los estudios neutralizados de la reproducción de leyes y modelos, que "explican" la "realidad" tal como se presenta, sin ninguna fisura, y donde el académico/a es alguien que posee la distancia subjetiva suficiente, sin intervención de lente ideológico o cultural alguno.

Por todo esto, predomina el modelo del intelectual que se rige en el hallazgo y la codificación, modelo que se ubica paralelamente con las empresas coloniales y las dinámicas de descubrimiento y codificación, sustentadoras de la colonialidad del poder frente a la alteridad. Al término "lidiar", agregaríamos la idea de dominar, controlar y deslegitimar. Más aún, esto también se evidencia en la 
poca presencia de académicos negros/as o indígenas en los recintos universitarios, lo que pone de manifiesto no sólo los mecanismos de racialización occidentales sino también la clausura de epistemes-otras, que valorizan experiencias culturales, mediaciones teóricas, narrativas y objetos heterodoxos.

Por ello la necesidad de una decolonización de la universidad, es decir, de hacer de ella un espacio que cuestione la mercantilización del conocimiento a través de la instrumentalización de la producción académica, que termine con las elites intelectuales y que deconstruya las visiones monopólicas del mundo para dar cuenta de la pluralidad de mundos-posibles, fuera de las cosmovisiones occidentales y modernas.

Eso se realiza replanteando no sólo los puntos de partida epistemológicos sino también a partir de cambios concretos a nivel institucional, que involucran diseños curriculares más flexibles y plurales (y no atenidos a los típicos campos disciplinares europeos), producción académica diversificada (es decir, no sólo a través de papers en revistas indexadas sino desde otro tipo de producciones que involucren el arte, la narrativa, lo visual, etc.) y dinámicas pedagógicas críticas que incluyan los factores socio-políticos y culturales en cualquier abordaje, desde un espacio de diálogo abierto e intercultural.

Así, proponer la descolonización de la universidad requiere una transculturización del conocimiento, o sea, construir un espacio de diálogo de saberes que dispute el eurocentrismo y occidentalismo impregnados en la academia monopólica. También requiere una transdisciplinariedad, donde los conocimientos heterodoxos representen ese "tercer espacio" necesario (BHABHA, 2002) para deconstruir los binomios maniqueos hegemónicos. Representan el sentido de un "tercio incluido", donde las epistemes-otras no son campos exotizados dentro de un conglomerado disperso de visiones a ser reconocidas y catalogadas como objetos ajenos a la agencia humana y las metodologías oficiales, sino que sean incluidas y puestas en diálogo en un mismo estatus ontológico con respecto a las epistemes monopólicas.

No se trata, por lo tanto, de reformar un sistema que desde su origen se muestra monocultural y monoracional. Existen varios ejemplos que podríamos aludir, que dan cuenta de propuestas pedagógicas y académicas alternativas desde una mirada decolonial. Por ejemplo, la Universidad Intercultural Amawatai Wasi y el Centro Yachay Munay en Ecuador, espacios universitarios desarrollados completamente desde una visión indígena (WALSH, 2005). El caso de la Universidad Andina Simón Bolívar, también en Ecuador, es una de las instituciones más representativas del pensamiento decolonial y que ha elaborado desde los códigos académicos formales una propuesta alternativa, tanto en lo curricular como lo investigativo (WALSH, 2005).

Finalmente, encontramos espacios educativos alternos entre grupos afroamericanos en Colombia (MENA, 2017) y experiencias entre mujeres de distintos sectores y grupos, orientadas en lo que se denomina como feminismos decoloniales (Bidaseca, et al, 2014). Estas experiencias indican dos movimientos ya mencionados: que los códigos académicos de la universidad pueden ser transformados desde adentro por la presencia de otros sujetos, como también que dicha institución no monopoliza la totalidad de las construcciones del saber; existen otros modos de institucionalidad posible a partir de epistemes alternativas. 
En resumen, descolonizar la universidad significa crear un espacio que Castro-Gomez (2007) denomina universidad rizomática, es decir, una institución que cuente con construcciones curriculares flexibles según los recorridos de cada estudiante, donde exista una oferta académica e investigativa que articule diversas epistemologías, y no sólo las corrientes de la academia europea monopólica.

Un tercer campo para analizar es la labor investigativa en el ámbito de la educación. Desde la antropología intercultural, la educación constituye uno de los medios más eficaces para la transmisión y aprendizaje de los elementos culturales, lingüísticos, comportamentales, laborales y ético/morales de una colectividad. Por medio de procesos educacionales, sea informal o formal, los pueblos y etnias comunican, perpetúan, desarrollan y recrean su saber-hacer en relación a la vida, al otro, a la naturaleza y a la sociedad como un todo. Ninguna cultura sobrevive si su cosmovisión no es transmitida, apropiada y transformada de generación en generación.

Como se puede deducir, en la rica diversidad cultural que caracteriza el continente americano, coexistían ilimitados modelos educativos, siendo gran parte de ellos no escolarizados y no universitarios. Pero sabemos que el proceso colonial ha intentado suplantar las culturas, epistemologías, saberes y valores distintos del sistema-mundo europeo. A lo largo de cinco siglos, la supremacía y universalidad de la modernidad a negado la diversidad y subalternado las diferencias como inferiores y atrasadas. Esta lógica fue establecida con la ayuda de un modelo educativo formal y escolarizado, que tiene la escuela y la universidad como portavoces máximas de la "cultura superior", subalternando lenguajes, epistemes y formas de construcción del saber distintas (MÉNDEZ, 2009).

En la actualidad, ese modelo educacional se encuentra difundido por todas partes, promoviendo la homogeneización de los cuerpos, subjetividades, saberes y valores, manteniendo la colonización del imaginario. Para reproducirse, este sistema cuenta con las universidades, en las cuáles, en la mayoría de los casos, impera un currículo formador pautado en paradigmas monoculturales, cientificistas y normalizadores de las diferencias (POZZER Y CECCHETTI, 2016).

Lo mismo ocurre con la epistemología y los métodos de investigación en educación. Imbricados en los condicionantes históricos del colonialismo y de la colonialidad, como subrayan Streck y Adams (2012), tales procesos investigativos continúan produciendo "herencias culturales de subordinación" que tienden a "perpetuarnos como imitadores". Los autores proponen que la labor investigativa en el campo de la educación debe procurar conquistar un camino propio capaz de potencializar los saberes y conocimientos de las diferentes culturas, pueblos, etnias y colectividades. Proponen, además, la búsqueda por fuentes pedagógicas de educadores y pensadores de nuestro continente, aún desconocidos por las actuales generaciones, para identificar modelos de resistencia y formas alternativas de desarrollo educacional.

Eso requiere producir y recuperar modos distintos de producción del conocimiento educativo, a través de formas de investigación que rompan con la dualidad sujeto-objeto, que inspiren cambios políticos y prácticas pedagógicas que enfrenten la colonialidad, abriendo puertas para el pensamientootro como estrategia epistémica para la producción académica diversificada.

Además, demanda el rompimiento del monopolio del saber recurrente de un canon educacional donde solamente algunos intelectuales - generalmente de los países europeos o estadunidenses - son utilizados como referencia de los proyectos de investigación en educación, Eso sólo sirve para 
reproducción de la matriz cultural y epistémica de la colonialidad, generando un verdadero desperdicio de las epistemologías originarias y del montante de saberes generados por las prácticas de educación popular desarrolladas por movimientos sociales en varios contextos.

\section{CONCLUSIONES}

En este trabajo hemos analizado cómo los dispositivos epistémicos tienen un rol central en la legitimación de saberes coloniales, que a su vez fundamentan prácticas sociales y educativas, imaginarios culturales y estructuraciones geo-políticas que rigen en el sistema-mundo. Más concretamente, las nociones de verdad objetiva, clasificación entre sujeto-objeto, humano-no humano, teoría-práctica, el lugar de la razón como epicentro de construcción del conocimiento, entre otros elementos, han sido naturalizados no sólo en términos de establecer un marco epistémico hegemónico que rige en espacios de enseñanza y producción académica, sino con el objetivo de excluir y estigmatizar otros modos de conocimiento, que ponen en jaque la homogeneidad ontológica de las lógicas coloniales.

El modelo de universidad contemporáneo fue puesto al servicio de ese sistema y responde a dinámicas de descubrimiento y codificación sustentadoras de la colonialidad del poder frente a la alteridad. Eso se evidencia en la exclusión de las epistemologías de los pueblos indígenas y afroamericanos en los espacios universitarios, lo que pone de manifiesto no sólo los mecanismos de racialización occidentales sino también la clausura de epistemes-otras, que valorizan experiencias culturales, mediaciones teóricas, narrativas y objetos heterodoxos.

Una epistemología decolonial desde un pensamiento-otro requiere que el trabajo investigativo en el campo de la educación se abra a modos de construcción de conocimiento heterodoxos, es decir, a partir de mediaciones alternativas que disten de responder a los cánones establecidos por la academia hegemónica con respecto a la legitimidad o no de un tipo de conocimiento "realmente" académico, objetivo, comprobable o verdadero.

Como hemos visto, este ejercicio no sólo implica una simple práctica de visibilización clasificatoria sino la construcción de espacios de empoderamiento socio-político, que ponen en evidencia la pluralidad de procesos de subjetivación, de voces y de identidades.

Una descolonización del saber implica transformar las prácticas académicas y educativas, no sólo para dar lugar a una multiplicidad cuantificable de elementos o discursos, sino de una transformación de sus códigos más elementales. Por ello, la necesidad de espacios de producción del saber que consideren diversas epistemologías y los saberes decurrentes de prácticas educativas alternativas que den cuenta de la pluralidad de formas de ser en el mundo.

Los establecimientos educativos y académicos deben dar cuenta de esta diversidad desde sus currículos, los cuales se rigen generalmente por la típica clasificación académica europea, dando lugar a instancias alternativas y transdisciplinares, que partan de estructuras libres, problemáticas sociales, diversificación de saberes, etc., hasta los contenidos de los procesos de producción. Se requiere, finalmente, de investigadores en educación tomen como punto de partida las demandas educativas de la sociedad y la articulación de sus propias voces para responder a ellas. 


\section{REFERENCIAS}

1. Bhabha, H. K. El lugar de la cultura. Buenos Aires: Manantial, 2002.

2. Bhabha, H. K. (Comp.) (2010). Nación y narración: entre la ilusión de una identidad y las diferencias culturales. Buenos Aires: Siglo XXI.

3. Canclini, N. Culturas híbridas. Buenos Aires: Paidós, 2001.

4. Canclini, N. Latinoamericanos buscando lugar en este siglo. Buenos Aires: Paidós, 2002.

5. Castro-Gomez, S. Deconolizar la universidad: la hybris del punto cero y el dialogo de saberes. In: Castro-Gómez, S.; Grosfoguel, R. El giro decolonial. Reflexiones para una verdad epistémica más allá del capitalismo global. Bogotá: Siglo del hombre editores, 2007.

6. Claros, L. Colonialidad y violencias cognitivas. Ensayos políticos-epistemológicos. La Paz: Muela del Diablo Editores, 2011.

7. Foucault, M. Microfísica do poder. Rio de Janeiro: Graal, 2008.

8. Lander, E. Ciencias sociales: saberes coloniales y eurocéntricos. In: Lander, E. La colonialidad del saber. Buenos Aires: CICCUS/CLACSO, 2011.

9. Mena, M. Educación teológica en grupos afrodescendientes. In: Panotto, N.; Preiswerk, M. (Eds). Otra educación teológica es posible. Nuevos sujetos y campos. Buenos Aires: SPT, 2017.

10. Méndez, J. M. M. Educação intercultural e justiça cultural. São Leopoldo: Nova Harmonia, 2009.

11. Mignolo, W. Desobediencia epistémica. Buenos Aires: Ediciones del Signo, 2010.

12. Mignolo, W. Historias locales/diseños globales. Madrid: Akal, 2013.

13. Palermo, Z. Conocimiento "otro" y conocimiento del otro en América Latina. Estud. - Cent. Estud. Av., Univ. Nac., n. 21, 2009, p. 79-90.

14. Palermo, Z. Itinerario. In: Palermo, Z; et al. Des/decolonizar la universidad. Ciudad Autónoma de Buenos Aires: Del Siglo, 2015, p. 15-39. 
15. Panikkar, R. Emanciparse de la ciencia. In: Ortiz-Asés, A.; Lanceros, P. La interpretación del mundo. Cuestiones para el tercer milenio. México: UAM, 2006, p. 53-73.

Panikkar, R. La puerta estrecha del conocimiento: sentidos, razón y fe. Barcelona: Herder, 2009.

17. Pozzer, A.; Cecchetti, E. Colonialidade do saber e formação docente: ensaios para episte(me)todologias interculturais. In: Hardt, L. S.; Moura, R. S. de. (Orgs.). Filosofias da educação: entre devires, interrupções e aberturas - outro mundo contemplado. Blumenau: Edifurb, 2016.

18. Prakash, G. Los estudios de la subalternidad como crítica post-colonial. In: Rivera Cusicanqui, S. Debates post coloniales: una introducción a los estudios de la subalternidad. Bogotá: SEPHIS, 2007.

Quijano, A. Colonialidad del poder y clasificación social. Journal of World-Systems Research, VI, 2, 2000, p. 342-386.

Quijano, A. Colonialidad del poder, eurocentrismo y América Latina. In: Lander, E. La colonialidad del saber. Buenos Aires: CICCUS/CLACSO, 2011, p. 219-264.

21. Richard, N. Intersectando latinoamérica con el latinoamericanismo: discurso académico y crítica colonial. In: Castro-Gómez, S.; Mendieta, E. (Eds). Teorías sin disciplina. Latinoamericanismo, poscolonialidad y globalización en debate. México: Miguel Ángel Porrúa, 1998, p.185-218.

22. Said, E. Orientalismo. Buenos Aires: Debate, 2016.

Segato, R. La crítica de la colonialidad en ocho ensayos. Buenos Aires: Prometeo, 2015.

24. Smith, L. T. A descolonizar las metodologías. Investigación y pueblos indígenas. Santiago: LOM, 2016.

25. Sousa Santos, B. de. Una epistemología del sur. Buenos Aires: Siglo XXI, 2009.

26. Sousa Santos, B. de. Para descolonizar Occidente. Más allá del pensamiento abismal. Buenos Aires: Prometeo libros/CLACSO, 2010.

27. Sousa Santos, B. de. De la mano de Alicia. Lo social y lo político en la posmodernidad. Bogotá: Siglo del Hombre Editores, 2012. 
Streck, D. R.; Adams, T. Pesquisa em educação: os movimentos sociais e a reconstrução epistemológica num contexto de colonialidad. Educação e Pesquisa, v. 38, n. 1, 2012, p. 243-257.

29. Walsh, C. (Ed.). Pensamiento crítico y matriz (de)colonial. Reflexiones latinoamericanas. Quito: Abya-Yala, 2005.

\section{Nicolás Esteban Panotto}

Doctor en Ciencias Sociales y Master en Antropología Social Política por la Facutad Latinoamericana de Ciencias Sociales. (FLACSO Argentina). Director del Grupo de Estudios Multidisciplinarios sobre Religión e Incidencia Pública (GEMRIP) Investigador Asociado del Instituto de Estudios Internacionales (INTE) de la Universidad Arturo Prat (Chile).

\section{Elcio Cecchetti}

Doutor em Educação pela Universidade Federal de Santa Catarina (UFSC). Professor do Programa de Mestrado em Educação da Unochapecó. Temas de Pesquisa: Políticas Públicas e Educação.

\section{Anderson Luiz Tedesco}

Doutor em Filosofia Pela Pontifícia Universidade Católica do Paraná - PUCPR. Professor da Universidade Comunitária de Chapecó - Unochapecó. Temáticas de Estudo: Ética e a Educação. Formação Humana e Tecnologia. 


\section{Como citar este documento:}

CECHETTI, Elcio; PANOTTO, Nicolás Esteban; TEDESCO, Anderson Luiz. Decolonizar el saber en la investigación en educación: el pensamiento-otro como estrategia epistémica para la producción académica diversificada. Reflexão e Ação, Santa Cruz do Sul, v. 28, n. 2, jun. 2020. ISSN 1982-9949. Disponível em: <https://online.unisc.br/seer/index.php/reflex/article/view/14298>. Acesso em: doi:https://doi.org/10.17058/rea.v28i2.14298. 